\title{
NLRP3 inflammasome as a target of berberine in experimental murine liver injury: interference with $\mathrm{P} 2 \mathrm{X}_{7}$ signalling
}

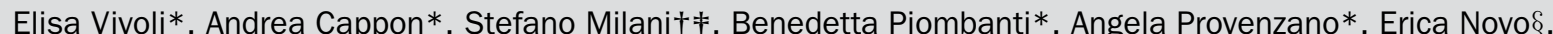
Alessio Masi ||, Nadia Navari*, Roberto Narducci\|, Guido Mannaioni\|, Gloriano Monetiף, Claudia P. Oliveira**, Maurizio Parola§ and Fabio Marra*キ

*Dipartimento di Medicina Sperimentale e Clinica, University of Florence, Florence, Italy

†Dipartimento di Scienze Biomediche, Sperimentali e Cliniche "Mario Serio", University of Florence, Florence, Italy

₹Centro di Ricerca Denothe, University of Florence, Florence, Italy

§Dipartimento di Scienze Cliniche e Biologiche, University of Turin, Turin, Italy

\|Dipartimento di Neuroscienze, Psicologia, Area del Farmaco e Salute del Bambino, University of Florence, Florence, Italy

IDipartimento di Scienze della Salute, University of Florence, Florence, Italy

**Department of Gastroenterology (LIM07), University of São Paulo School of Medicine, São Paulo, Brazil

\begin{abstract}
Berberine (BRB) is commonly used in herbal medicine, but its mechanisms of action are poorly understood. In the present study, we tested BRB in steatohepatitis induced by a methionine- and choline-deficient (MCD) diet, in acute acetaminophen intoxication and in cultured murine macrophages. BRB markedly improved parameters of liver injury and necroinflammation induced by the MCD diet, although increased mortality was observed by mechanisms independent of bacterial infections or plasma levels of BRB. The MCD diet induced up-regulation of all components of the NLRP3 (NACHT, LRR and PYD domain-containing protein 3) inflammasome, and increased hepatic levels of mature IL-1 $\beta$ (interleukin $1 \beta$ ). All of these parameters were significantly reduced in mice treated with BRB. In mice administered an acetaminophen overdose, a model dependent on inflammasome activation, BRB reduced mortality and ALT (alanine aminotransferase) elevation, and limited the expression of inflammasome components. In vitro, LPS (lipopolysaccharide)-induced activation of NLRP3 inflammasome in RAW264.7 murine macrophages was markedly decreased by pre-incubation with BRB. BRB significantly limited the activation of the purinergic receptor $\mathrm{P} 2 \mathrm{X}_{7}$, involved in the late phases of inflammasome activation. Upon P2X $\mathrm{X}_{7}$ knockdown, the ability of BRB to block LPS-induced secretion of IL-1 $\beta$ was lost. These data indicate that administration of BRB ameliorates inflammation and injury in two unrelated murine models of liver damage. We demonstrate for the first time that BRB interferes with activation of the NLRP3 inflammasome pathway in vivo and in vitro, through a mechanism based on interference with activation of $\mathrm{P}_{2} \mathrm{X}_{7}$, a purinergic receptor involved in inflammasome activation.
\end{abstract}

Key words: acetaminophen toxicity, chemokines, cytokines, LPS, macrophages, inflammation, non-alcoholic steatohepatitis.

\section{INTRODUCTION}

Non-alcoholic fatty liver disease, including NASH (nonalcoholic steatohepatitis), is the most prevalent form of liver disease in Western countries [1]. More importantly, a diagnosis of NASH is associated with a higher risk of overall mortality and of liver-related mortality, indicating that strategies to prevent progression of liver injury are needed [2]. However, no clearly effective pharmacological therapies are approved for this condition, and patients often self-administer herbal or dietary supplements (HDS) that are advertised to be beneficial to this and possibly other hepatic abnormalities. Although the use of HDS is increasing dramatically, diffusion of these compounds is not accompanied by an adequate knowledge of their mechanism of

Abbreviations: ALT, alanine aminotransferase; APAP, acetaminophen; ASC, apoptosis-associated speck-like protein containing a caspase recruitment domain; BRB, berberine; CCL2, CC chemokine ligand 2; GAPDH, glyceraldehyde-3-phosphate dehydrogenase; HDS, herbal or dietary supplements; I $\kappa$ B $\alpha$, inhibitor of NF- $\kappa$ B $\alpha$; IL, interleukin; i.p., intraperitoneally; LPS, lipopolysaccharide; MCD, methionine- and choline-deficient; NASH, non-alcoholic steatohepatitis; NF- $\kappa$ B, nuclear factor $\kappa$ B; NLRP3, NACHT, LRR and PYD domain-containing protein 3; $\mathrm{RT}$, reverse transcription; TGF- $\beta$, transforming growth factor $\beta$; TNF $\alpha$, tumour necrosis factor $\alpha$.

Correspondence: Dr Fabio Marra (email fabio.marra@unifi.it). 
action, and this limits the possible development of purified active molecules and/or their recommendation on a larger scale [3].

Berberine (BRB) is the main alkaloid component of several plants used for centuries in traditional Chinese and Ayurvedic medicine, including Berberis aquifolium or Coptis chinensis [4]. This chemical is a quaternary ammonium salt that belongs to the protoberberine group of isoquinoline alkaloids, and can be found in the root and bark of herbs, such as goldenseal, berberis and Chinese goldthread [5]. Alone or in combination with other HDS, $\mathrm{BRB}$ extracts are one of the top selling products in the U.S.A. and in Europe. The success of BRB started along with reports of its multiple pharmacological and biochemical properties, including cholesterol-lowering [6], anti-diabetic [7], antioxidant [8], hepatoprotective [9], anti-inflammatory [10], antibacterial [11] and anti-tumoral activities [12]. Although many different mechanisms of action have been hypothesized, only a few of them have been validated with appropriate experimental techniques.

Inflammation plays a relevant role in the pathogenesis of different forms of acute and chronic liver injury, including NASH [13]. In the present study, we show that BRB exerts potent antiinflammatory actions in two unrelated in vivo models of liver injury, and report for the first time that BRB inhibits the activation of the NLRP3 (NACHT, LRR and PYD domain-containing protein 3) inflammasome pathway, through interference with the purinergic receptor $\mathrm{P} 2 \mathrm{X}_{7}$.

\section{EXPERIMENTAL}

\section{Reagents}

Unless indicated otherwise, all chemicals were purchased from Sigma Chemical Co.

\section{Animals and experimental protocol}

Wild-type C57BL/6 mice were obtained from Charles River Laboratories. In all experiments, 6-8-week-old male mice were used. At least six mice for control conditions and eight mice for experimental conditions were analysed. All animals were treated with humane care and experimental protocols performed according to established guidelines (Guide for the Care and Use of Laboratory Animals, NIH publication No. 86-23) after approval by the local regulatory authorities.

\section{Steatohepatitis model}

Mice were fed on a methionine- and choline-deficient (MCD) diet (Laboratori Dottori Piccioni) for 28 days, as described previously [14]. A methionine- and choline-sufficient control diet was supplemented with choline chloride $(2 \mathrm{~g} / \mathrm{kg}$ diet $)$ and D,Lmethionine $(3 \mathrm{~g} / \mathrm{kg}$ diet $)$. BRB $(5 \mathrm{mg} / \mathrm{kg})$ or its vehicle $(10 \%$ $\mathrm{DMSO} /$ saline) were injected i.p. (intraperitoneally) every day for 28 days. Mice had unrestricted access to food and water. Body weight was recorded weekly. At the end of the study protocol, mice were anaesthetized and killed by exsanguination. Blood was collected and centrifuged, and serum was stored for further analysis. Livers were rapidly dissected out, weighed, snap-frozen in liquid nitrogen and kept at $80^{\circ} \mathrm{C}$ for RNA and protein extrac- tion. A portion of the liver was immediately fixed in formalin for histological analysis.

\section{Acetaminophen (APAP) intoxication}

Mice were starved $12-15 \mathrm{~h}$ before the treatment with APAP. The drug $(500 \mathrm{mg} / \mathrm{kg})$ or its vehicle (saline) were administered i.p. BRB ( 1 or $5 \mathrm{mg} / \mathrm{kg}$ ) or its vehicle (10\% DMSO in saline) were injected i.p., 24 and $2 \mathrm{~h}$ before APAP treatment. In one experiment, mice were observed for $72 \mathrm{~h}$ to record animals survival. In a parallel experiment, mice were killed at different time points ( 6 and $12 \mathrm{~h}$ ), by exsanguination under anaesthesia. After collecting blood, livers were excised. Samples obtained after $6 \mathrm{~h}$ were freshly analysed for determination of glutathione (GSH), whereas those at $12 \mathrm{~h}$ were snap-frozen in liquid nitrogen and kept at $80^{\circ} \mathrm{C}$ for DNA and protein extraction.

\section{ALT (alanine aminotransferase) activity and cholesterol levels}

Blood samples were centrifuged at $1500 \mathrm{~g}$ for $10 \mathrm{~min}$ at $4{ }^{\circ} \mathrm{C}$, and serum was stored at $-20^{\circ} \mathrm{C}$ until analysis. Serum ALT activity was determined using Reflotron ${ }^{\circledR}$ Plus system (Roche Diagnostics). Serum cholesterol was determined using a Dimension Vista $^{\circledR}$ system (Siemens Healthcare).

\section{Liver histology}

A portion of liver tissue was fixed by immersion in $10 \%$ buffered formalin $(\mathrm{pH} 7.4)$ for $24 \mathrm{~h}$. The fixed tissue was dehydrated in graded ethanol, paraffin-embedded and sectioned at a thickness of $4 \mu \mathrm{m}$. Haematoxylin/eosin staining was performed as described previously [14]. Liver histology was evaluated by an experienced hepatopathologist (S.M.) blinded to the type of treatment received by the animals. Necroinflammation was graded focusing on zone 3 as 0 (absent), 1 (sparse or mild, focal), 2 (noticeable) and 3 (severe).

\section{RNA isolation and quantitative PCR}

Procedures for hepatic RNA isolation and quantitative real-time PCR have been described in detail elsewhere [14]. GAPDH (glyceraldehyde-3-phosphate dehydrogenase) was used as housekeeping gene. FAM (6-carboxyfluorescein)-labelled probes and specific primers were obtained as Assays-on-Demand (Applied Biosystems). Supplementary Table S1 presents a list of the primers used. Relative gene expression was calculated as $2^{-\triangle C T}$ $\left(\Delta C_{\mathrm{T}}=C_{\mathrm{T}}\right.$ of the target gene $-C_{\mathrm{T}}$ of GAPDH).

\section{Measurement of serum BRB concentration by LC-MS/MS analysis}

Plasma samples were measured using a HPLC PerkinElmer Series 200 micropump apparatus and chromatographed using a $75 \mathrm{~mm} \times 2.0 \mathrm{~mm}$ internal diameter, $4 \mu \mathrm{m}$ particle size $80 \AA$ ( $1 \AA ̊=0.1 \mathrm{~nm}$ ) Synergi Polar-RP column (Phenomenex). Mobile phase A consisted of water containing 3\% acetonitrile and $0.1 \%$ formic acid, and mobile phase $\mathrm{B}$ was acetonitrile containing $3 \%$ water and $0.1 \%$ formic acid. An elution gradient was performed from 5 to $90 \%$ phase B in $12 \mathrm{~min}$. B was held at $90 \%$ for $3 \mathrm{~min}$, and then brought back to the starting value in $1 \mathrm{~min}$. The equilibration time before the next injection was $10 \mathrm{~min}$. The eluate, at a 
flow rate of $200 \mu \mathrm{l} / \mathrm{min}$, was directly introduced into the LC-MS interface. The LC-MS/MS system consisted of a PerkinElmer Sciex API 365 triple-quadrupole mass spectrometer (Thornhill) equipped with a Turbo IonSpray Interface. The compounds were ionized by positive-ion electrospray and detected using MRM (multiple reaction monitoring). The needle and orifice voltage were adjusted to $5.5 \mathrm{kV}$ and $66 \mathrm{~V}$ respectively. The drying gas flow rate and temperature were $7 \mathrm{l} / \mathrm{min}$ and $300^{\circ} \mathrm{C}$ respectively. The first and third quadrupole mass analysers were operated at unit mass resolution. Fragmentation was accomplished with a collision energy of $51 \mathrm{eV}$ for BRB and $32 \mathrm{eV}$ for internal standard (ranitidine). Nitrogen was used as the collision gas at a CGT (collision gas thickness) of $2.6 \times 10^{15}$ molecules $\cdot \mathrm{cm}^{-2}$. The ion transition monitored were $m / z \quad 336 \rightarrow 292,336 \rightarrow 320$ for BRB and $m / z 315 \rightarrow 175$ for ranitidine.

\section{LPS (lipopolysaccharide)-stimulated RAW264.7 cells}

RAW264.7 murine macrophages were kindly provided by Dr Elisabetta Rovida (Dipartimento di Scienze Biomediche, Sperimentali e Cliniche "Mario Serio", University of Florence, Florence, Italy) and were cultured in DMEM (Dulbecco's modified Eagle's medium) containing 10\% (v/v) FBS, 100 units/ml penicillin and $100 \mu \mathrm{g} / \mathrm{ml}$ streptomycin at $37^{\circ} \mathrm{C}$ in $5 \% \mathrm{CO}_{2}$. After plating in 12 -well plates (500000 cells/well) cells were treated with LPS $(1 \mu \mathrm{g} / \mathrm{ml})$ following or not BRB pre-treatment $(20 \mu \mathrm{M})$ $2 \mathrm{~h}$ before LPS. Cells were collected 2 and $8 \mathrm{~h}$ after LPS for RNA isolation. In other experiments, after $24 \mathrm{~h}$ the supernatants were collected for protein assay.

\section{Intracellular calcium measurement}

RAW264.7 cells were incubated in a solution containing $150 \mathrm{mM}$ $\mathrm{NaCl}, 10 \mathrm{mM}$ Hepes, $3 \mathrm{mM} \mathrm{KCl}, 2 \mathrm{mM} \mathrm{CaCl}_{2}, 1 \mathrm{mM} \mathrm{MgCl}_{2}$ and $10 \mathrm{mM}$ glucose $(\mathrm{pH} 7.3)$, at $37^{\circ} \mathrm{C}$ for $30 \mathrm{~min}$ with the $5 \mu \mathrm{M}$ cellpermeant calcium dye Fluo-3 acetoxymethyl ester (Molecular Probes). To facilitate Fluo-3 solubilization in aqueous medium, $1 \mathrm{mM}$ pluronic F-127 was added (Molecular Probes). The dye was allowed to de-esterify for $30 \mathrm{~min}$ at room temperature. Coverslips containing Fluo-3-loaded cells were subsequently transferred to a continuously perfused microscope stage for imaging where they were perfused for $10 \mathrm{~min}$ with Hepes solution before performing calcium imaging recordings. Images were visualized with a $20 \times$ Fluor objective and acquired every $2 \mathrm{~s}$. Exposure time was set to $200 \mathrm{~ms}$ and excitation was provided by a PE-1 system (CoolLED) equipped with a $470 \pm 30 \mathrm{~nm}$ LED. Fluo-3 fluorescence was recorded through a bandpass filter $(535 \pm 25 \mathrm{~nm})$ with a Photometrics Coolsnap HP Camera set at $-20^{\circ} \mathrm{C}$. Fluorescence intensity was measured using Imaging Workbench 6 software (Indec BioSystems) and expressed as the ratio of $\left(F-F_{0}\right) / F_{0}$, where $F_{0}$ is the baseline fluorescence intensity in cell bodies before any treatment. All measurements were corrected for background fluorescence. Increases in fluorescence ratio greater than 0.2 were considered significant. Experiments were performed at room temperature.

\section{Gene silencing}

Cultured RAW264.7 cells were serum-deprived and transfected with non-targeting siRNA (siGENOME Non-Targeting siRNA Pool, GE Dharmacon) or siRNA targeting murine $\mathrm{P}_{2} \mathrm{X}_{7}$ (siRNASmart Pool, GE Dharmacon) using an Amaxa device, as described previously [15]. After $48 \mathrm{~h}$, cells were collected for analysis of $\mathrm{P}_{2} \mathrm{X}_{7}$ expression by quantitative RT (reverse transcription)-PCR or incubated with LPS or its vehicle, in the presence or absence of BRB, for an additional $24 \mathrm{~h}$.

\section{IL-1 $\beta$ (interleukin 1 $\beta$ ) assay}

Liver tissues were lysed at $4{ }^{\circ} \mathrm{C}$ with lysis buffer $(1 \%$ Triton $\mathrm{X}$ $100,50 \mathrm{mmol} / 1 \mathrm{Tris} / \mathrm{HCl}, \mathrm{pH} 7.4,150 \mathrm{mmol} / \mathrm{l} \mathrm{NaCl}, 1 \mathrm{mmol} / \mathrm{l}$ EDTA, $1 \mathrm{mmol} / 1$ sodium orthovanadate, $2 \mathrm{mmol} / \mathrm{l} \mathrm{PMSF}$ and $1 \mathrm{mmol} / 1$ each of leupeptin and pepstatin) in a Polytron mixer. Tissue extracts were centrifuged at $12000 \mathrm{~g}$ for $10 \mathrm{~min}$, and the supernatant was used for mature IL- $1 \beta$ assay, as indicated by the manufacturer (R\&D Systems).

For experiments in RAW264.7 cells, media conditioned for $24 \mathrm{~h}$ in the presence of appropriate stimuli were frozen at $-20^{\circ} \mathrm{C}$ and used for IL- $1 \beta$ assay. Data are expressed as $\mathrm{pg} / \mathrm{ml}$ after normalization of the amount of protein in each sample.

\section{Western blot analysis}

Isolation of total protein from RAW264.7 cells and subsequent Western blot analysis was performed according to previously published procedures [15].

\section{Statistical analysis}

Unless stated otherwise, data are expressed as means \pm S.E.M. Comparisons of different conditions was performed by Student's $t$ test. Histological scores of inflammation were compared using the Mann-Whitney $U$ test. Survival curves were evaluated using the Kaplan-Meier method. $P$ values less than 0.05 were considered significant.

\section{RESULTS}

\section{BRB reduces necroinflammation in experimental steatohepatitis}

We first explored the effects of BRB on the development of steatohepatitis induced by administration of a MCD diet for 4 weeks. In all mice administered the MCD diet, body weight was markedly and significantly decreased (Table 1 ). The reduction in liver weight was significantly less pronounced in mice receiving BRB together with the MCD diet. No evident changes in the general behaviour of mice was observed comparing animals receiving BRB or its vehicle. As is well established, this diet caused a rapid and marked accumulation of fat in hepatocytes, with a predominant macrovesicular pattern, and an evident infiltration with inflammatory cells, often detected in foci or surrounding groups of hepatocytes with microvesicular steatosis, as lipogranulomas [14]. Treatment with BRB did not modify the grade of steatosis, whereas it resulted in a marked improvement of inflammation associated with the MCD diet, as was evident when analysing 
Table 1 Effects of berberine on liver and body weight in mice fed on a methionine- and choline-deficient diet for 4 weeks

Data are means \pm S.D. $* P<0.05$ compared with $C D+$ vehicle. ${ }^{\wedge} P<0.05$ compared with $M C D+$ vehicle. ${ }^{\#} P=0.056$ compared with $\mathrm{MCD}+$ vehicle.

\begin{tabular}{llll}
\hline Treatment & $\begin{array}{l}\text { Body weight } \\
\text { (g) }\end{array}$ & $\begin{array}{l}\text { Liver weight } \\
(\mathbf{g})\end{array}$ & $\begin{array}{l}\text { Liver/body } \\
\text { weight ratio (\%) }\end{array}$ \\
\hline CD+vehicle & $25.4 \pm 1.4$ & $1.17 \pm 0.18$ & $4.6 \pm 0.8$ \\
CD+BRB & $23.0 \pm 1.2$ & $1.06 \pm 0.13$ & $4.6 \pm 0.8$ \\
MCD+vehicle & $15.8 \pm 1.1^{*}$ & $0.61 \pm 0.09 *$ & $3.9 \pm 0.7 *$ \\
MCD+BRB & $16.8 \pm 1.3^{*}$ & $0.76 \pm 0.11^{* \wedge}$ & $4.5 \pm 0.6 \#$ \\
\hline
\end{tabular}

the histological pictures (Figure 1A). These effects were associated with a marked and significant reduction in ALT levels in comparison with mice receiving only the MCD diet (Figure 1B). When the histological scores of necroinflammation were evaluated, the marked and significant increase associated with MCD diet-induced steatohepatitis was virtually abolished by treatment with BRB, resulting in scores similar to those measured in mice administered the control diet (Figure 1C). In addition, BRB reduced apoptosis induced by the MCD diet (Supplementary Figure $\mathrm{S} 1)$. These data indicate that BRB treatment induces a marked reduction of necroinflammation in mice administered with the MCD diet. Of note, no significant effects on any of these parameters or on hepatic histology were observed when mice were treated with BRB alone.

Steatohepatitis triggers a multicellular response, involving liver resident and infiltrating cells, resulting in reprogramming of different genes to co-ordinate a complex inflammatory response [13]. To assess the effects of BRB on these factors, we evaluated intrahepatic expression of genes involved in liver inflammation and repair. A 3-fold increase in the expression of CD11B, a marker of leucocyte activation, was observed in mice receiving the $M C D$ diet, whereas a significant reduction was found in animals treated with BRB (Figure 2A). A similar behaviour was observed when expression of $\mathrm{TNF} \alpha$ (tumour necrosis factor $\alpha$ ), which is pivotally involved in the pathogenesis of NASH, was analysed (Figure 2B). Inflammation in steatohepatitis is characterized by a polarization of macrophages towards a pro-inflammatory, M1-type, phenotype, which contributes to disease progression and fibrogenesis [16]. These aspects were recapitulated by the significant increase in expression of CCL2 (CC chemokine ligand 2) and NOS2 (nitric oxide synthase 2), the inducible form of nitric oxide synthase (Figures $2 \mathrm{C}$ and 2D), in mice receiving the $\mathrm{MCD}$ diet. $\mathrm{BRB}$ administration significantly reduced the expression levels of these genes. Chronic liver injury, including that caused by NASH, leads to progressive fibrosis and ultimately cirrhosis. A fibrogenic phenotype is not apparent after 4 weeks on the MCD diet, but activation of fibrogenic factors such as TGF- $\beta$ (transforming growth factor $\beta$ ) or type I procollagen (Figures $2 \mathrm{E}$ and $2 \mathrm{~F}$ ) was already evident at the gene expression level. BRB treatment reduced TGF- $\beta$ expression by approximately $50 \%$ in comparison with untreated animals. Similarly, the marked and significant increase in type I procollagen gene expression was reduced in mice receiving the herbal supplement together with the MCD diet. Collectively, these data indicate that

\begin{tabular}{c} 
A \\
$\begin{array}{c}\text { Control } \\
\text { diet }\end{array}$ \\
\hline MCD
\end{tabular}
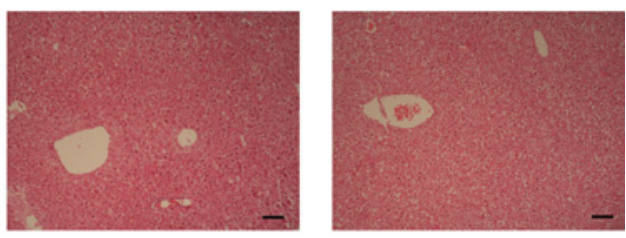

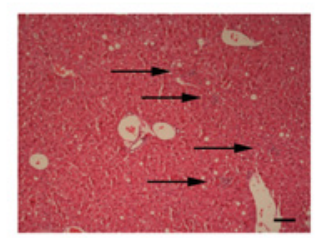

Vehicle

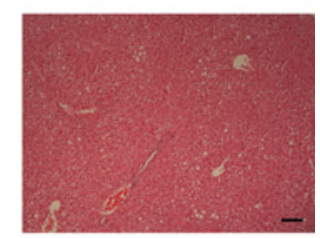

Berberine
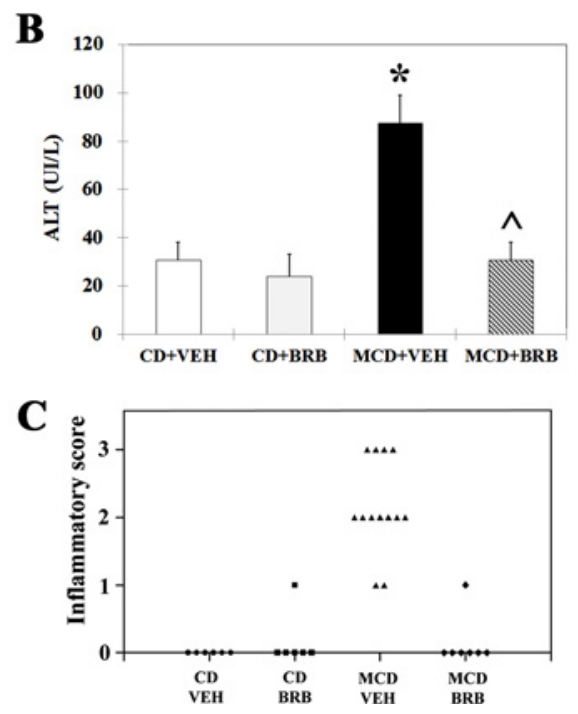

Figure 1 Berberine administration reduces injury and inflammation in a murine model of steatohepatitis

Male C57BL/ 6 mice were administered a diet deficient in methionine and choline (MCD) or a control diet (CD) for 4 weeks, together with BRB ( $5 \mathrm{mg} / \mathrm{kg} /$ day) or its vehicle (VEH). (A) Haematoxylin and eosin staining of liver tissue indicates normal liver tissue in mice receiving the control diet irrespective of co-administration of vehicle or BRB. Animals on the MCD diet developed a typical picture of steatohepatitis together with marked infiltration of inflammatory cells (arrows). The inflammatory aspects were markedly decreased in mice administered the MCD diet and receiving BRB. Scale bar, $100 \mu \mathrm{m}$. (B) At the time of killing, blood was drawn and ALT levels were measured in the different groups of mice, as indicated. (C) The hepatic inflammatory score was determined as indicated in the Experimental section. Results are individual scores for mice analysed in the different groups. $* P<0.05$ compared with $\mathrm{CD}+\mathrm{VEH} ;{ }^{\wedge} \mathrm{P}<0.05$ compared with MCD+VEH.

BRB ameliorates the inflammatory phenotype and limits expression of fibrogenic genes associated with experimental steatohepatitis induced by a MCD diet.

\section{Administration of BRB together with the MCD diet increases animal mortality}

To establish whether BRB could effectively limit deposition of fibrotic tissue after prolonged exposure to the MCD diet, we intended to analyse a group of animals for 8 weeks, a time point where a typical pericentral 'chickenwire' fibrosis is observed. 

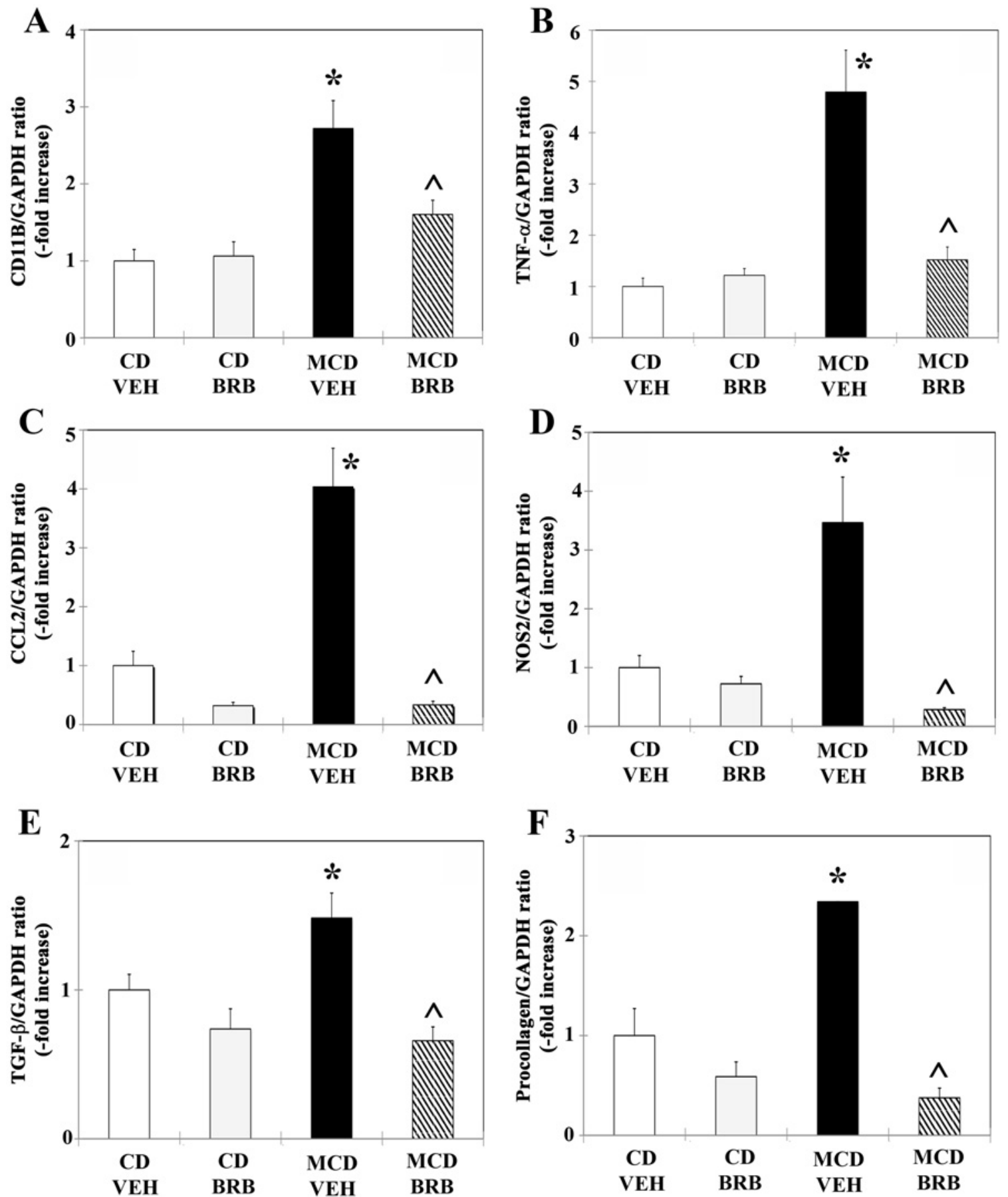

Figure 2 The induction of genes involved in hepatic inflammation and repair during steatohepatitis is reduced by BRB administration

Male C57BL/ 6 mice were administered a diet deficient in methionine and choline (MCD) or a control diet (CD) for 4 weeks, together with BRB ( $5 \mathrm{mg} / \mathrm{kg}$ per day) or its vehicle (VEH). At the end of the experiment, RNA was isolated from liver tissue and expression of CD11B (A), TNF $\alpha(\mathbf{B}), \operatorname{CCL} 2(\mathbf{C})$, NOS2 (D), TGF- $\beta(\mathbf{E})$ and $\alpha 1$ procollagen I (F) was measured by quantitative RT-PCR as described in the Experimental section. ${ }^{*} P<0.05$ compared with $\mathrm{CD}+\mathrm{VEH} ;{ }^{\wedge} P<0.05$ compared with MCD+VEH.

Unfortunately, we observed that animals treated with BRB when administered the MCD diet showed an excess of mortality during the first weeks of study compared with those receiving vehicle (Figure 3A). At the 4-week time point, more than half of the mice on $\mathrm{BRB}$ and the MCD diet died, whereas this number was negligible in those receiving the MCD diet alone. Of note, no mice receiving $\mathrm{BRB}$ died while on the control diet (Figure $3 \mathrm{~A}$ ), thus ruling out a possible toxic effect of the BRB preparation used. 
A

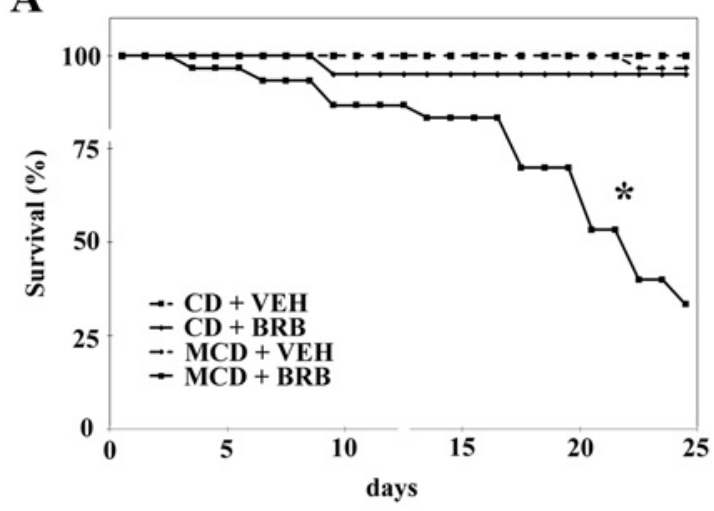

B

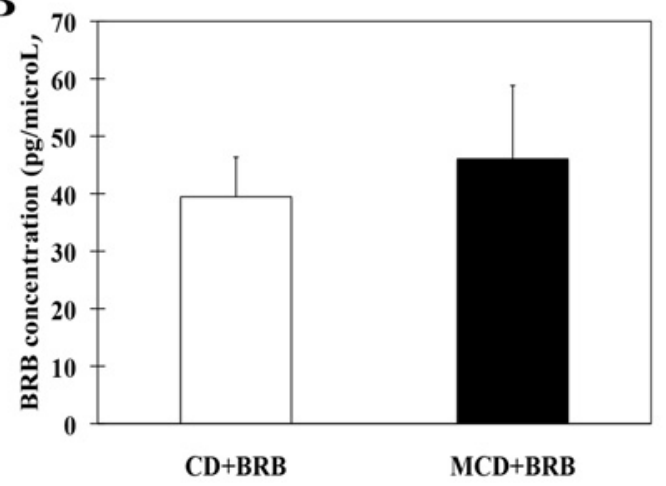

C

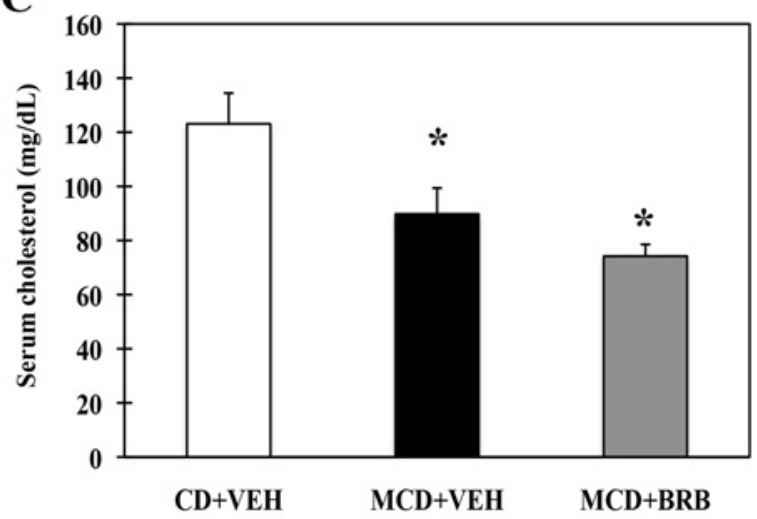

D

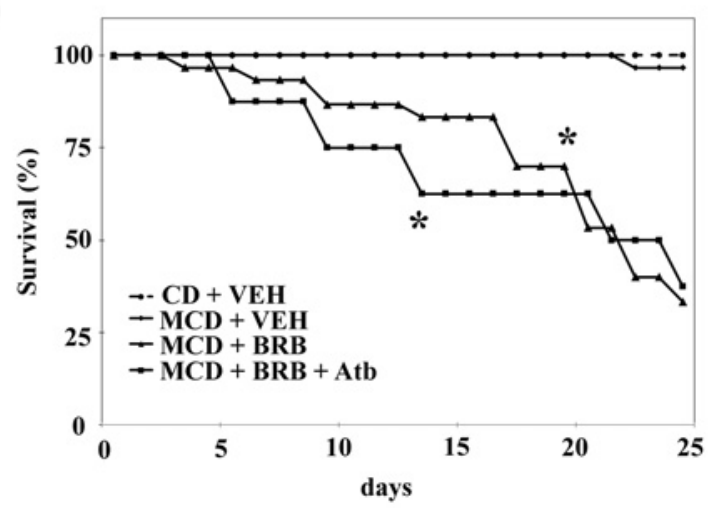

Figure 3 Increased mortality of mice exposed to MCD together with berberine

Male C57BL/ 6 mice were administered a diet deficient in methionine and choline (MCD) or a control diet (CD) for 4 weeks, together with BRB $(5 \mathrm{mg} / \mathrm{kg}$ per day) or its vehicle (VEH). (A) Survival of mice in the different experimental groups as indicated as a percentage of the starting number. $* P<0.05$ compared with all other groups. (B) At the time of killing, blood was drawn and levels of total cholesterol were measured in the different groups of mice, as indicated. $* P<0.05$ compared with CD+VEH. (C) The plasma levels of BRB were measured by MS in mice receiving the control diet (CD) or the $M C D$ diet. (D) Mice treated with $C D$ and vehicle $(C D+V E H), M C D$ and vehicle (MCD+VEH) or MCD and BRB (MCD+BRB) with or without amoxicillin/clavulanate, a broad-spectrum antibiotic (MCD+BRB+Atb). Survival of mice in the different experimental groups is indicated as percentage of the starting number. $* P<0.05$ compared with MCD+VEH.

At necroptic examination, the animals that died upon administration of MCD and BRB showed bilateral effusions in the lungs, associated with inflammatory cell infiltration. To establish whether bacterial infections could be responsible for the death of this group of animals, we repeated the experiment administering a broad-spectrum antibiotic treatment, with the hypothesis that increased susceptibility to bacterial infection might contribute to the negative outcome. However, co-administration of amoxicillin/clavulanate did not significantly affect mice survival (Figure 3D).

BRB has been reported to lower serum cholesterol levels, an effect which is also observed in animals administered a MCD diet [17]. To exclude the possibility that excessively low cholesterol levels had a negative effect on animal survival, we measured serum cholesterol levels in different groups of mice. Whereas the MCD diet induced a significant decrease in serum cholesterol levels (Figure 3B), further decreases induced by coadministration of BRB were only modest and non-significant, indicating that mortality could not be explained by dramatically low cholesterol levels in the MCD plus BRB group. We finally considered that an altered $\mathrm{BRB}$ metabolism in mice receiving the MCD diet could result in elevated, and potentially toxic, levels of BRB. We set up an MS-based method to measure BRB levels in serum, and compared the levels of this compound in mice receiving BRB together with the two types of diet (Figure 3C). However, BRB levels were comparable in the two groups of animals, showing that excessive circulating levels of BRB are not related to the increased mortality observed in the MCD diet group. Considering the amelioration of steatohepatitis in mice receiving BRB, these results indicate that association of BRB with a MCD diet increases mortality of mice by a mechanism unrelated to the liver, and independent of bacterial infections, low cholesterol levels or excessive circulating BRB.

\section{BRB reduces activation of the NLRP3} inflammasome pathway in two independent models Accumulating evidence indicates the possible role of the inflammasome pathway in the regulation of liver damage and repair induced by different conditions, including steatohepatitis. We evaluated whether the remarkable decrease in the inflammatory 
response in mice receiving BRB was associated with changes in activation of the inflammasome pathway and/or in the expression of its individual components. As reported previously [18], intrahepatic expression of IL- $1 \beta$, a potent pro-inflammatory cytokine regulated by inflammasome activation, was significantly increased in mice administered a MCD diet for 4 weeks (Figure 4A). Of note, co-treatment with BRB caused a marked and significant reduction in IL- $1 \beta$ gene expression, which returned to levels comparable with those of control mice. A similar behaviour was observed with expression of single components of the inflammasome cascade, such as caspase 1, NLRP3, ASC (apoptosis-associated speck-like protein containing a caspase recruitment domain), and pannexin 1, a pore associated with the purinergic $\mathrm{P}_{2} \mathrm{X}_{7}$ receptor was analysed (Figures $4 \mathrm{~B}-4 \mathrm{E}$ ). Because regulation of mRNA levels is not necessarily associated with changes in the final multimolecular complex or in its activity, we measured the levels of mature IL- $1 \beta$ in the livers of mice subjected to the different treatments. IL- $1 \beta$ was significantly increased by the MCD diet, and this increase was no longer evident in animals receiving BRB. Together, these data indicate that BRB interferes with the assembly of the inflammasome pathway induced by experimental steatohepatitis.

To provide further in vivo evidence for the modulation of the inflammasome pathways by BRB, we tested its effects in mice with APAP-induced hepatotoxicity, where liver damage has been previously shown to be dependent on inflammasome activation [19]. Pre-treatment of mice with two different doses of BRB $\left(1 \mathrm{mg} \cdot \mathrm{kg}^{-1}\right.$ and $\left.5 \mathrm{mg} \cdot \mathrm{kg}^{-1}\right)$ markedly and significantly reduced the mortality caused by APAP overdose (Figure 5A). Accordingly, the marked elevation in ALT levels induced by APAP was significantly reduced by BRB, confirming the protective effects observed on animal mortality (Figure 5B). These effects were associated with a significant reduction in the expression of genes related to the inflammasome pathway, specifically those encoding caspase 1 and IL-1 $\beta$ (Figures 5C and 5D). To rule out the possibility that the effects of BRB were related to modifications of APAP metabolism, we measured the intrahepatic levels of glutathione, as a reliable indicator of the accumulation of $\mathrm{N}$ acetyl- $p$-benzoquinone imine, the metabolite of APAP responsible for the formation of adducts and for hepatocellular damage. The decrease in glutathione levels induced by APAP was not significantly modified by BRB, thus ruling out possible effects on APAP metabolism. These data indicate that BRB administration results in a reduced activation of the inflammasome pathway in two unrelated murine models of liver injury.

\section{BRB blocks inflammasome assembly and activation in cultured murine macrophages}

Because BRB is a potent anti-inflammatory agent, in vivo experiments do not allow to establish whether reduced inflammasome activation is a factor contributing to reduced inflammation, or merely a consequence of a reduced recruitment of inflammatory cells dependent on other mechanisms [20]. To clarify this critical issue, we assessed the effects of BRB in cultured murine macrophages exposed to LPS. LPS determined a marked induction of mRNA encoding inflammasome components, including IL- $1 \beta$, NLRP3 or ASC (Figures 6A-6C), and all of these effects were significantly inhibited by BRB pre-treatment. More importantly, BRB inhibited by approximately $60 \%$ LPS-stimulated secretion of mature IL- $1 \beta$ in the culture medium (Figure $6 \mathrm{~F}$ ). Activation of $\mathrm{NF}-\kappa \mathrm{B}$ (nuclear factor $\kappa \mathrm{B}$ ) contributes to the early transcription of genes encoding inflammasome components [21], and BRB has been found to suppress the inflammatory response by inhibiting NF- $\kappa$ B activation in many tissues $[22,23]$. To verify whether modulation of inflammasome activation by BRB was dependent on an interaction with NF- $\kappa \mathrm{B}$, we assessed activation of this pathway by measuring the protein levels of $\mathrm{I} \kappa \mathrm{B} \alpha$ (inhibitor of NF- $\kappa \mathrm{B} \alpha$ ) in LPS-treated cells (Figure 6E). As expected, LPS reduced the levels of $\mathrm{I} \kappa \mathrm{B} \alpha$, the regulatory protein which prevents NF- $\kappa \mathrm{B}$ migration to the nucleus and activation of pro-inflammatory genes. Pre-treatment of RAW264.7 cells with $\mathrm{BRB}$ did not inhibit NF- $\kappa \mathrm{B}$ activation, as indicated by levels of $\mathrm{I} \kappa \mathrm{B} \alpha$ comparable with those of cells receiving vehicle, following LPS treatment. To provide additional evidence for the involvement of NF- $\kappa \mathrm{B}$-independent pathway(s) in the regulation of inflammasome by BRB, we measured the effects of BRB on LPS-induced expression of TNF $\alpha$, a cytokine regulated by $\mathrm{NF}-\kappa \mathrm{B}$ activation in an inflammasome-independent fashion. The 10 -fold increase in TNF $\alpha$ mRNA levels, induced by LPS in RAW264.7 macrophages, was not significantly modified by BRB treatment (Figure 6D). Collectively, these results indicate that BRB inhibits activation of NRLP3 inflammasome with an action independent of NF- $\kappa$ B.

\section{BRB interferes with activation of the purinergic receptor $\mathrm{P}_{2} \mathrm{X}_{\mathbf{7}}$}

Activation of the purinergic receptor $\mathrm{P} 2 \mathrm{X}_{7}$ is pivotal to provide a 'second signal' which leads to inflammasome assembly and activation [24]. We hypothesized that BRB could interfere with binding of damage-associated molecular patterns, such as ATP, to $\mathrm{P} 2 \mathrm{X}_{7}$, thus limiting the inflammatory response associated with liver damage. When RAW264.7 murine macrophages were exposed to benzyl-ATP, a selective $\mathrm{P}_{2} \mathrm{X}_{7}$ receptor agonist, an evident calcium transient was observed, indicating activation of downstream signalling eventually contributing to inflammasome activation (Figure 7A). Pre-treatment with BRB markedly and significantly attenuated benzyl-ATP-induced calcium efflux, indicating an inhibitory interaction with $\mathrm{P}_{2} \mathrm{X}_{7}$-mediated signalling (Figures $7 \mathrm{~A}$ and $7 \mathrm{~B}$ ). To provide evidence that $\mathrm{P} 2 \mathrm{X}_{7}$ is a major target of BRB, we evaluated the effects of genetic knockdown of $\mathrm{P} 2 \mathrm{X}_{7}$ on the ability of BRB to block IL- $1 \beta$ secretion. After P2X knockdown, LPS was still able to significantly up-regulate IL$1 \beta$ secretion in RAW264.7 cells, although less efficiently than in cells transfected with non-targeting siRNA. In contrast, the ability of BRB to block LPS-induced IL- $1 \beta$ secretion was lost in cells silenced for $\mathrm{P}_{2} \mathrm{X}_{7}$, indicating the critical role of this receptor in mediating the inhibitory effects of BRB on inflammasome activation in this model.

\section{DISCUSSION}

The use of HDS for the treatment of different disorders, including liver diseases, has expanded tremendously, and data from 2007 

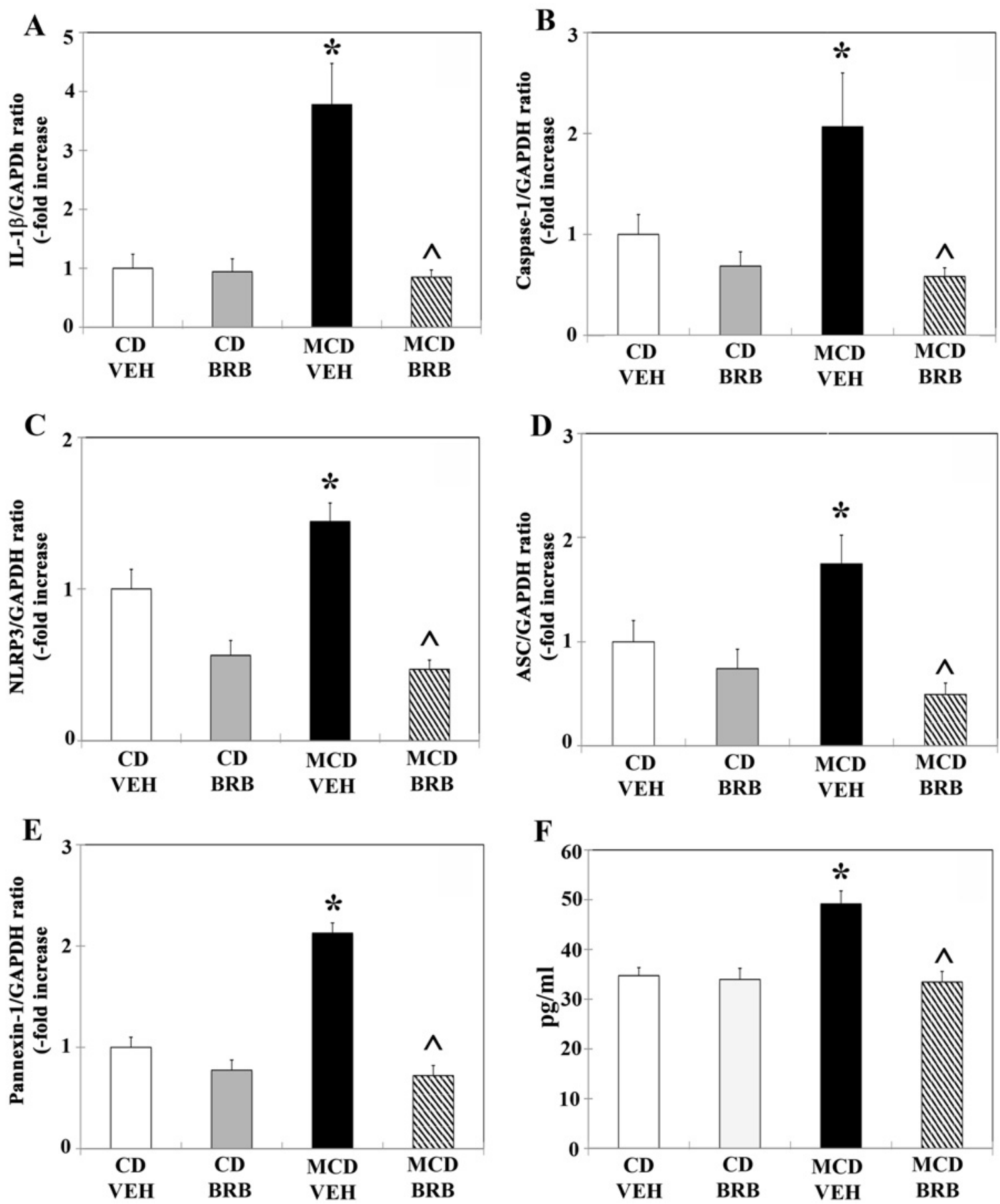

Figure 4 Activation of the inflammasome system associated with experimental steatohepatitis is modulated by berberine

Male C57BL/ 6 mice were administered a diet deficient in methionine and choline (MCD) or a control diet (CD) for 4 weeks, together with BRB ( $5 \mathrm{mg} / \mathrm{kg} /$ day) or its vehicle (VEH). (A-E) At the end of the experiment, RNA was isolated from liver tissue and expression of IL-1 $\beta(\mathbf{A})$, caspase 1 (B), NLRP3 (C), ASC (D) and pannexin-1 (E) was measured by quantitative RT-PCR as described in the Experimental section. (F) Hepatic levels of mature IL-1 $\beta$ were tested in the different groups using ELISA, as described in the Experimental section. ${ }^{*} P<0.05$ compared with $\mathrm{CD}+\mathrm{VEH} ; \wedge P<0.05$ compared with $\mathrm{MCD}+\mathrm{VEH}$. 
A

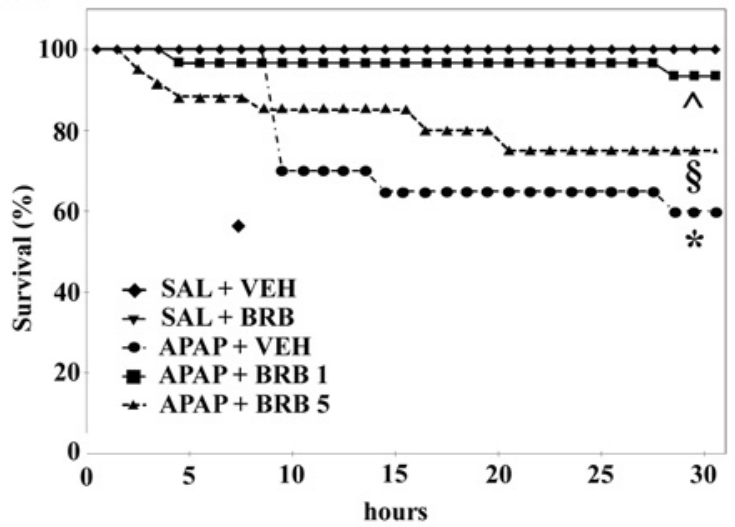

C

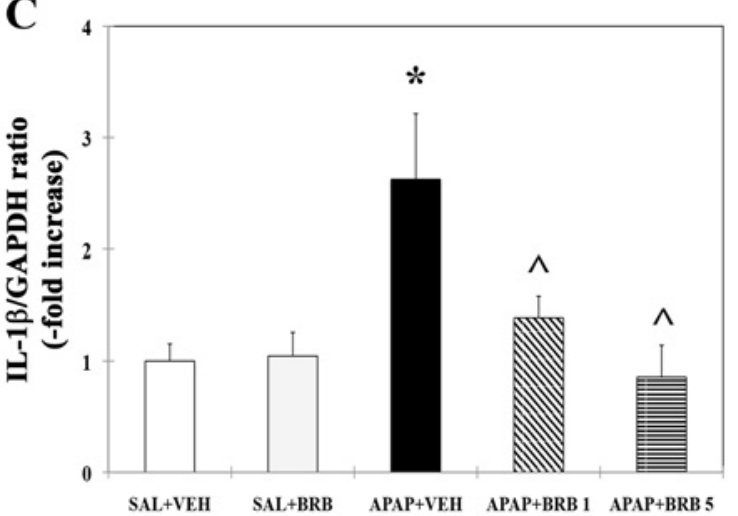

$\mathbf{E}$

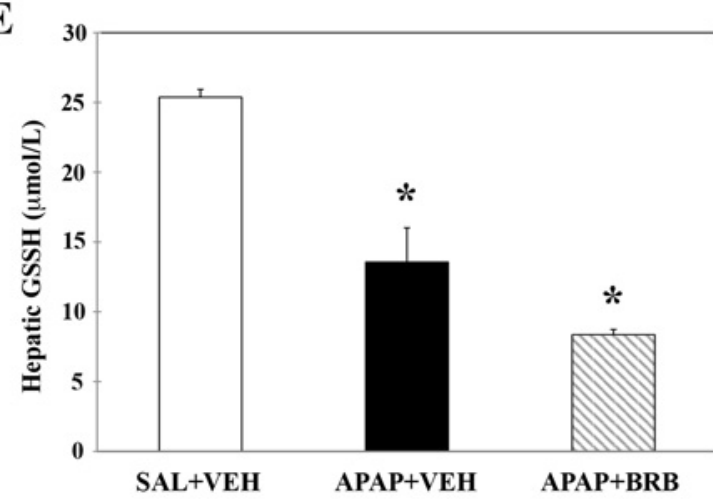

B

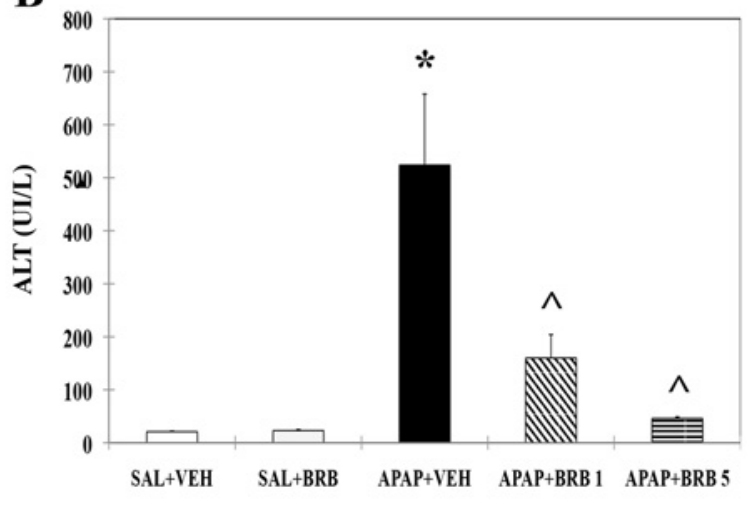

D

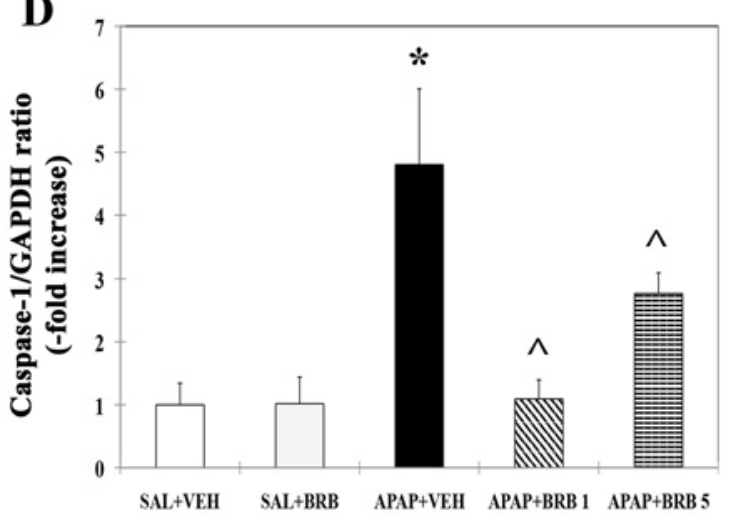

Figure 5 Berberine protects mice from acetaminophen (APAP) toxicity and limits inflammasome activation

Mice were administered a single dose of APAP $(500 \mathrm{mg} / \mathrm{kg}$ i.p.) or saline (SAL), together with $1 \mathrm{or} 5 \mathrm{mg} / \mathrm{kg}$ BRB, as indicated, or its vehicle (VEH). (A) Survival of mice in the different experimental groups indicated as percentage of the starting number. $* P<0.05$ compared with $\mathrm{SAL}+\mathrm{VEH} ;{ }^{\wedge} P<0.05$ compared with $\mathrm{APAP}+\mathrm{VEH} ; \S P=0.058$ compared with APAP+VEH). (B) At the time of killing, blood was drawn and ALT levels measured in the different groups of mice, as indicated. (C and D) RNA was isolated from liver tissue and expression of IL-1 $\beta$ (C) or caspase 1 (D) was measured by quantitative RT-PCR as described in the Experimental section. (E) Intrahepatic levels of glutathione were measured in control mice and in mice receiving acetaminophen with or without BRB, $6 \mathrm{~h}$ after administration of APAP. $* P<0.05$ compared with control; $\wedge P<0.05$ compared with APAP+VEH.

indicate that as many as $17 \%$ of Americans have used at least once a natural product at least once (https://nccih.nih.gov/research/ statistics/NHIS/2012/key-findings; accessed July 2015). Although undoubtedly some natural compounds show efficacy for the treatment of liver disease, information on their mechanisms of action is still scarce, and lack of these lines of evidence limits the eventual development of novel drugs based on HDS. BRB is found in tea and in several over-the-counter HDS, and ranks among the top ten most commonly used herbal supplements in children in the U.S.A. [25]. In the present study, we demonstrate 


\section{A}
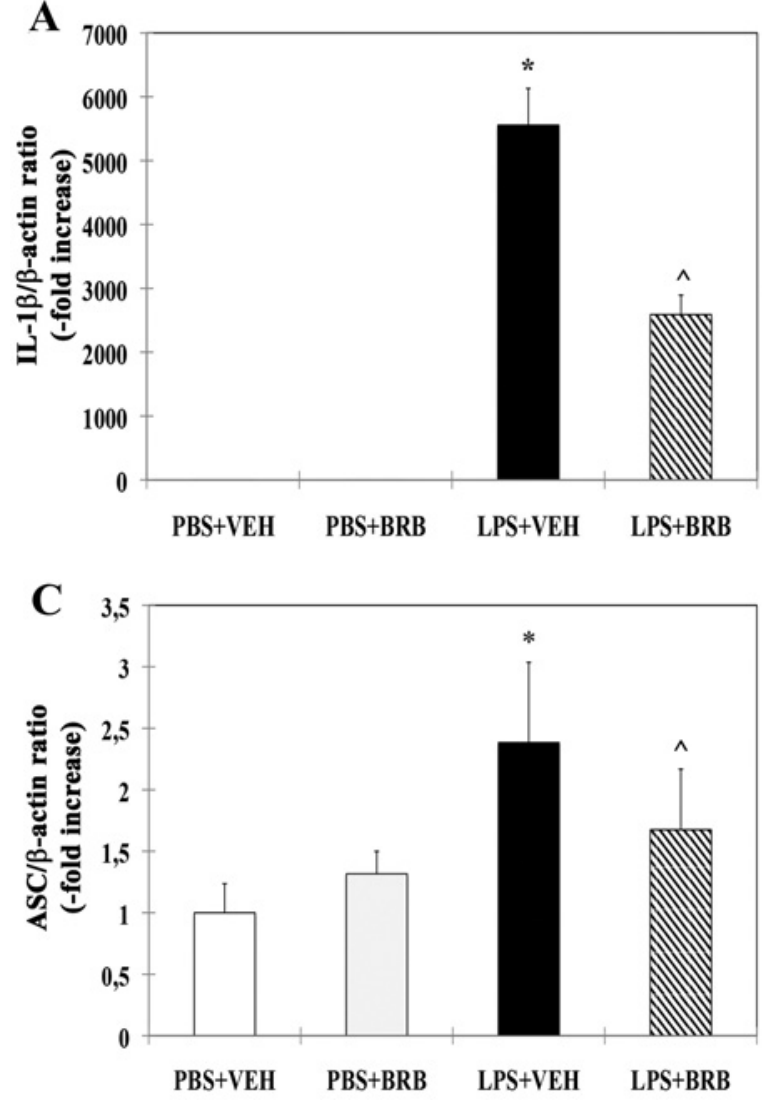

$\mathbf{E}$
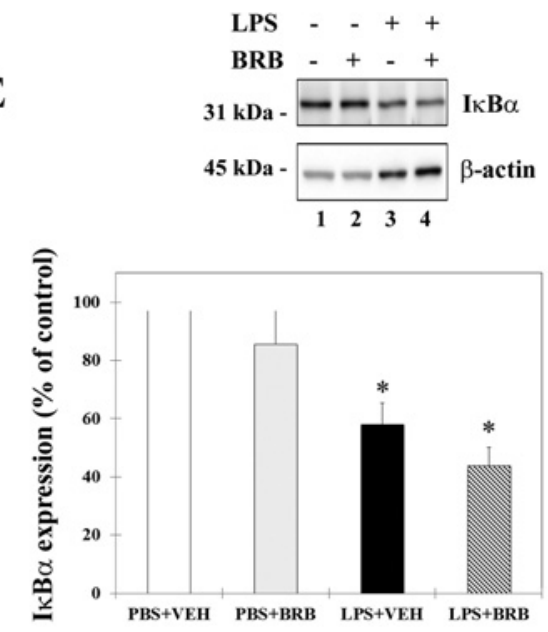
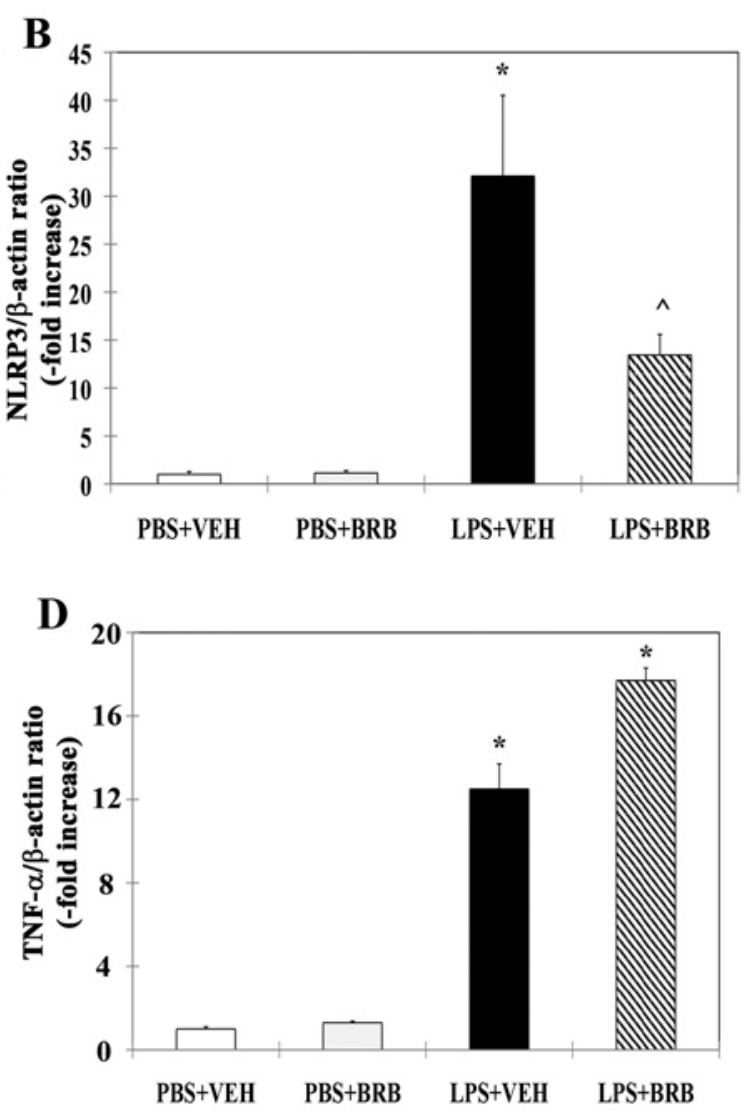

$\mathbf{F}$

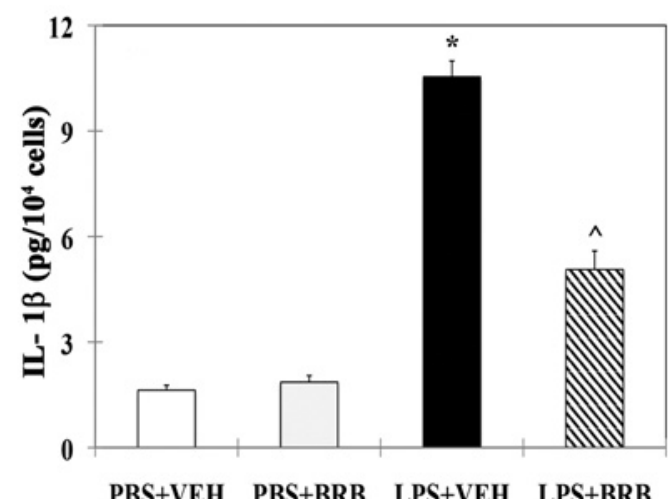

Figure 6 Berberine modulates inflammasome activation in cultured murine macrophages

RAW264.7 cells were incubated with LPS or PBS in the presence of BRB $(20 \mu \mathrm{M})$ or its vehicle (VEH) for $2 \mathrm{~h}$. (A-D) RNA was isolated from liver tissue and expression of IL-1 $\beta(\mathbf{A})$, NLRP3 (B), ASC (C) or TNF- $\alpha$ (D) was measured by quantitative RT-PCR as described in the Experimental section. (E) Cells were lysed and expression of $I_{\kappa} \mathrm{B} \alpha$ or of the housekeeping gene $\beta$-actin was analysed by Western blotting (upper panel). The lower panel shows quantification of Western blot signals in three independent experiments (means \pm S.E.M.). (F) Levels of mature IL-1 $\beta$ were measured in the supernatants of the different experimental conditions using ELISA, as described in the Experimental section. $* P<0.05$ compared with PBS+VEH; $\wedge P<0.05$ compared with LPS+VEH. 

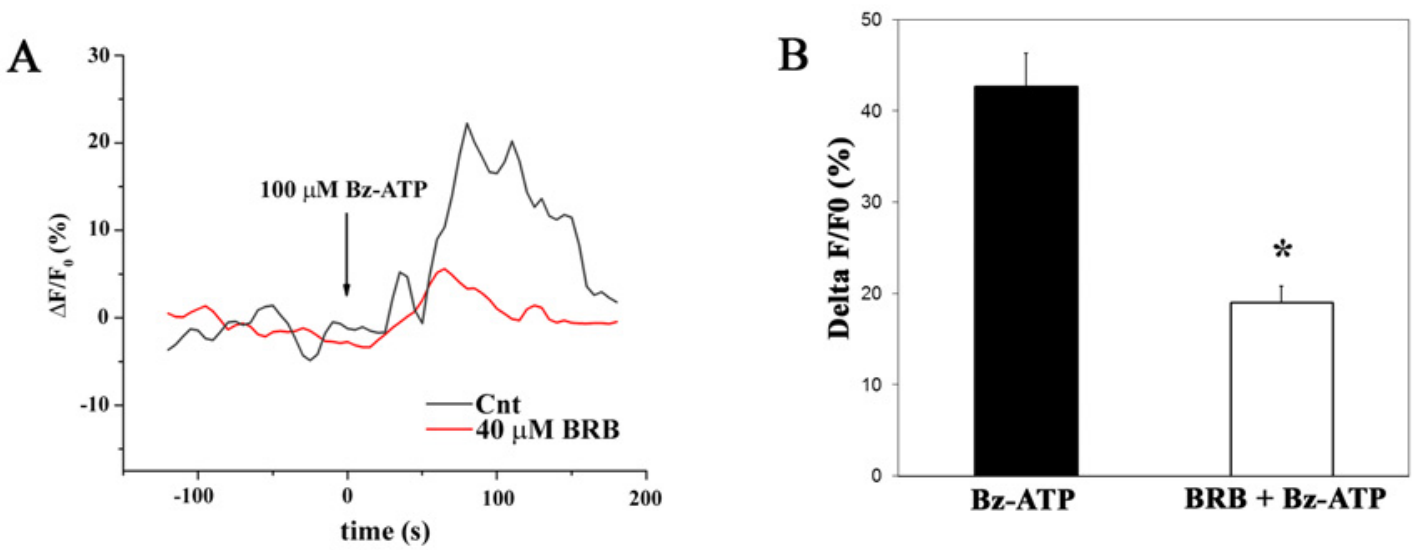

C

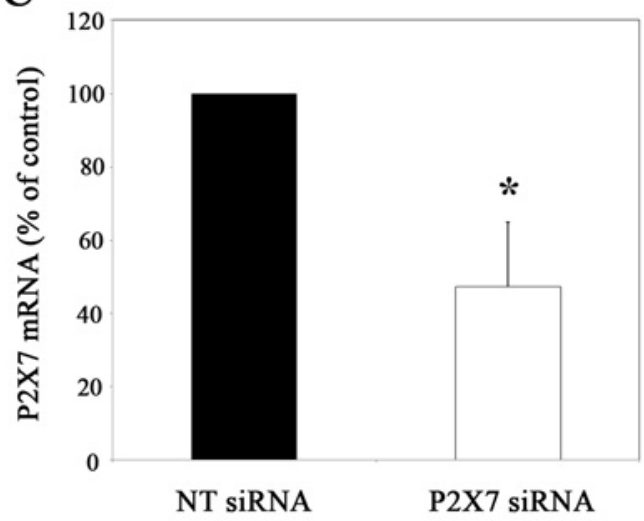

D

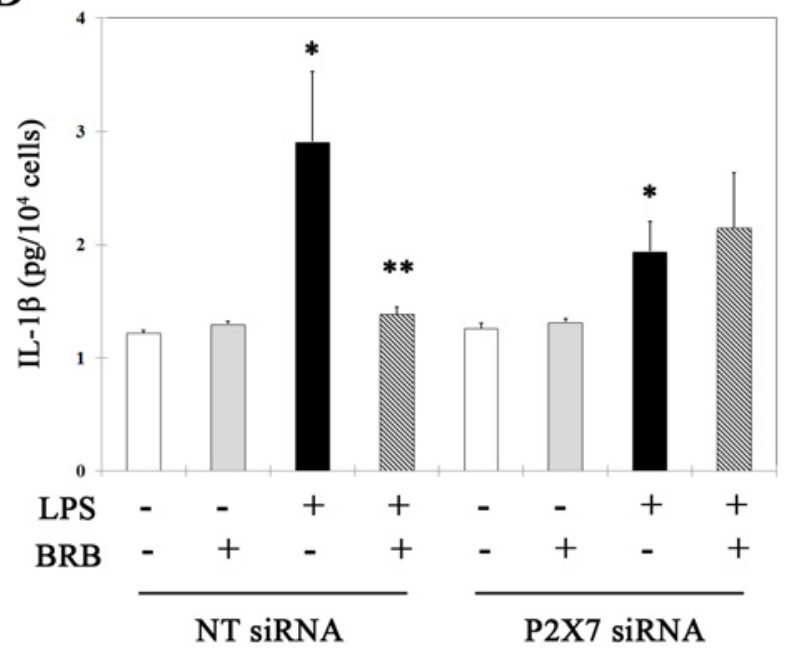

Figure 7 Berberine interferes with intracellular signalling generated by activation of the purinergic receptor $\mathbf{P 2 X}_{7}$

(A) RAW264.7 cells were loaded with Fluo-3 to measure intracellular calcium levels. Representative traces of cells exposed to benzyl-ATP without (black trace) or with (red trace) $40 \mu \mathrm{M}$ BRB pre-incubation. Time is indicated on the $x$-axis, fluorescence intensity variations expressed as $\left(F-F_{0}\right) / F_{0}$ are on the $y$-axis. (B) Maximal intracellular calcium peak recorded after benzyl-ATP application in the two different experimental conditions ( $n=37$ and 18 respectively). The highest peak amplitude was measured within 2 min of challenging cells with benzyl-ATP, whereas baseline values were obtained by averaging calcium levels recorded 1 min before benzyl-ATP administration. $* P<0.0001$ compared with control. (C) RAW264.7 cells were transfected with non-targeting siRNA or siRNA targeting the purinergic receptor $\mathrm{P}_{2} \mathrm{X}_{7}$, as indicated. After $48 \mathrm{~h}$, expression levels of P2X $\mathrm{X}_{7}$ were assessed by quantitative RT-PCR (means \pm S.E.M., $n=4$ ). (D) RAW264.7 cells silenced as described in (C) were incubated with LPS in the presence or absence of $20 \mu \mathrm{M}$ BRB for $24 \mathrm{~h}$, as indicated. Levels of mature IL- $1 \beta$ were measured in the supernatants of the different experimental conditions using ELISA, as described in the Experimental section. $* P<0.05$ compared with control. $* * P<0.05$ compared with LPS without BRB. Results are means \pm S.E.M. $(n=4)$.

for the first time that the NLRP3 inflammasome is a target of the action of $\mathrm{BRB}$ in vivo and in vitro, providing evidence for a novel mechanism underlying the potent anti-inflammatory action of this compound.

Starting from available data suggesting a hepatoprotective role of BRB in liver disease [9], we first investigated the effects of this compound in mice administered a MCD diet, a widely accepted model of experimental steatohepatitis. In fact, NASH represents a condition where no clearly effective treatments are yet available, and, on the other hand, patients with metabolic abnormalities are very likely to take different HDS. Administration of BRB to mice on a MCD diet resulted in a striking reduction of several parameters of intrahepatic inflammation and in a marked amelioration of liver histology. Of note, these changes were also associated with a reduced activation of fibrogenic genes, which eventually lead to tissue scarring. It should be pointed out that, surprisingly, the amelioration in the hepatic phenotype was associated with increased animal mortality. This precluded us from extending the investigation to longer time points to assess the possible effects of BRB on fibrosis in this model. Although the negative impact of BRB on survival was apparently independently of the actions on the liver, it should be considered that only a fraction of animals initially administered MCD diet and BRB were available for final analysis. Therefore future experiments with different administration schedules of BRB and/or different models of steatohepatitis are warranted. 
We extensively investigated why co-exposure to a MCD diet and BRB results in such a negative effect on survival, which was independent of the effects on the liver and of the BRB preparation itself, which did not exhibit any toxic effects when administered alone. It has been reported that, in HepG2 cells, BRB is able to induce apoptotic and autophagic cell death [26], but in the present study, BRB actually reduced apoptosis induced in the liver by the MCD diet. We ruled out an accumulation of BRB by measuring its circulating levels through a novel MS-based assay method. Nonetheless, it should be considered that in these experiments plasma BRB concentrations were approximately 6-fold higher than those measured when administered to patients with nonalcoholic fatty liver disease [27]. Thus the possibility that higher plasma levels and/or the route of administration (i.p. compared with oral) may have had an impact on toxicity cannot be ruled out. We also excluded the possibility that excessively low cholesterol levels had been reached in animals treated with the MCD diet and BRB, in the light of the cholesterol-lowering properties of this compound. As some of the mice dying while on BRB and the MCD diet had signs suggesting pneumonia at necropsy, we repeated the experiment administering antibacterial agents to mice, but no effects on mortality were observed. Although the ultimate reason for this unforeseen effect remains unclear, it is possible that in the setting of cachexia associated with the MCD diet, the dramatic reduction in antimicrobial defence caused by BRB favoured opportunistic infections not responsive to common antibacterial agents. An alternative, but not mutually exclusive, hypothesis is that the neurotoxic effects of BRB reported in some experimental settings [28] were maximized by the MCD diet by mechanisms independent of plasma levels of $\mathrm{BRB}$, for example via generation of metabolites.

The dramatic anti-inflammatory effect of BRB in the MCD dietary model prompted us to explore its possible interference with the inflammasome system. Inflammasomes are a group of multimeric protein complexes triggered by a range of stimuli generated during infection, tissue damage or metabolic imbalance [29]. Upon formation of the protein complex, the inflammasome activates caspase 1 , which proteolytically cleaves the precursors of the pro-inflammatory cytokines IL- $1 \beta$ and IL-18. In addition, inflammasome activation causes a rapid pro-inflammatory form of cell death called pyroptosis, which is relevant in the process of so-called 'sterile inflammation', observed in different conditions of liver injury including NASH [21]. This is confirmed by recent data by Wree et al. [30], who demonstrated that mice expressing a constitutively active form of NLRP3 under control of the endogenous NLPR3 promoter develop extensive liver inflammation, hepatocyte pyroptosis and liver fibrosis. In mice with steatohepatitis induced by a MCD diet, administration of BRB clearly modulated inflammasome activation, as indicated by significantly reduced gene expression of its components and, more importantly, by a marked reduction of the intrahepatic accumulation of mature IL-1 $\beta$. Moreover, BRB reduced inflammasome activation and tissue damage also in mice with APAP-induced liver damage, a model of injury which has been closely associated with inflammasome activation [19], where a lower dose of $\mathrm{BRB}$ was even more effective. Thus experiments in two independent models of 'sterile inflammation' indicate that modulation of the NLRP3 inflammasome may be considered as a previously unrecognized action of BRB, possibly contributing to its antiinflammatory effects.

The anti-inflammatory action of BRB has been described previously, and has been attributed to modulation of different pathways, including NF- $\kappa \mathrm{B}[22,23]$. We then conducted in vitro experiments using murine macrophages to establish whether the reduced activation of NLRP3 inflammasome was a direct effect of BRB or rather the result of inflammation dampening dependent on other pathways. The observation that BRB is capable of potently reducing activation of all inflammasome components in isolated cells exposed to LPS strongly suggests that this pathway is a bona fide target of BRB. On the other hand, no significant effects of $\mathrm{BRB}$ on the activation of NF- $\kappa \mathrm{B}$ were found, indicating that, although this pathway is indispensable for the early phases of NLRP3 inflammasome activation (signal 1 [31]), it does not represent the major target of BRB in this context.

For these reasons, we focused on the molecular mechanisms that are implicated in the later stages of inflammasome activation, where a second signal, possibly generated by damaged cells, results in changes in calcium and potassium fluxes, leading to the final assembly of the multimolecular inflammasome complex [32]. Among the molecules implicated in the generation of this signal 2, we focused on ATP and its cognate purinergic receptor $\mathrm{P}_{2} \mathrm{X}_{7}$, on the basis of the structural characteristics of BRB, which, as an alkaloid, could possibly interfere with this receptor family [33]. Remarkably, the intracellular calcium flux induced by exposure of murine macrophages to an ATP analogue was markedly dampened by pre-treatment with $\mathrm{BRB}$, indicating that interference with signal 2 of inflammasome assembly represents a novel target implicated in the action of BRB in this setting. These data are in agreement with those reported previously using compounds structurally similar to BRB, which displayed noncompetitive inhibition of the $\mathrm{P} 2 \mathrm{X}_{7}$ receptor [34,35].

Additional future work will be required to explore additional aspects highlighted by the present study. Henao-Mejia et al. [36] have reported that genetic deletion of inflammasome components favours NASH through interaction with the intestinal microbiota [36]. It will be interesting to establish whether BRB administration results in changes in gut ecology, including possible actions on the microbiota itself and/or on the immunity or barrier function of the intestine. On more clinical grounds, the observation that BRB increases animal mortality when associated with a MCD diet suggests that possible toxic effects of this supplement should be carefully reassessed in humans, as several HDS contain BRB. Although the MCD model reproduces the histological changes associated with NASH, severe deficiency of methionine and choline is infrequent in humans. However, choline deficiency has been reported in alcoholics and in obese patients, who, on the basis of our data, might potentially be at higher risk of BRB toxicity.

In conclusion, administration of BRB reduces inflammation and modulates the activation of the inflammasome pathway in a model of experimental steatohepatitis and after acetaminophen intoxication in mice. These effects are associated with blockade of calcium flux induced by the purinergic receptor $\mathrm{P} 2 \mathrm{X}_{7}$, identifying a novel molecular mechanism by which BRB 
limits inflammation. The present study highlights the relevance of a better understanding of the pharmacological mechanisms of commonly used HDS, which could be useful for the development of novel therapeutic tools and for comprehension of toxicity associated with some of these compounds.

\section{CLINICAL PERSPECTIVES}

- The use of herbal and dietary supplements for the treatment of liver diseases is growing, but information on the molecular mechanisms underlying their actions is limited.

- We show that berberine, one of the more widely used herbal medicines, limits the activation of the NLRP3 inflammasome, a pathway involved in the pathogenesis of inflammation and injury in many liver diseases. The action of berberine is mediated by interference with the purinergic receptor $\mathrm{P} 2 \mathrm{X}_{7}$. Berberine decreased the survival of mice treated with a methionine- and choline-deficient diet, suggesting the need to reassess possible toxic effects if this compound in humans.

- Understanding how berberine acts is critical for the development of novel therapeutic tools, possibly exploiting the identification of the role of $\mathrm{P}_{2} \mathrm{X}_{7}$ in this context.

\section{AUTHOR CONTRIBUTION}

Elisa Vivoli planned and carried out experiments and data analysis and drafted the paper. Andrea Cappon, Benedetta Piombanti, Angela Provenzano, Erica Novo and Nadia Navari carried out experiments. Claudia Oliveira carried out experiments and drafted the paper. Stefano Milani conducted histological assessment and scoring, data analysis. Alessio Masi, Roberto Narducci and Guido Mannaioni planned and carried out experiments on the role of $\mathrm{P} 2 \mathrm{X}_{7}$ and data analysis, and drafted the paper. Gloriano Moneti carried out studies with MS and interpretation thereof, and drafted the paper. Maurizio Parola planned experiments, drafted the paper and acquired funding. Fabio Marra planned the study and experiments and data analysis, wrote the final paper and acquired funding.

\section{ACKNOWLEDGEMENTS}

We are indebted to Stefania Madiai for technical help with histological slide preparation.

FUNDING
This work was supported by grants from the Italian Ministry
for Research [projects Progetti di Ricerca di Interesse Nazionale
(PRIN) and Fondo per gli Investimenti della Ricerca di Base
(FIRB)], the European Community's Seventh Framework Programme
FP7/2007-2013) [grant number HEALTH-F2-2009-241762] for the
Project FLIP (Fatty Liver: Inhibition of Progression), the Foundation
Cariplo (all to F.M.) and from CRT (Cassa di Risparmio di Torino) (to
M.P.).

\section{REFERENCES}

1 Corey, K.E. and Kaplan, L.M. (2014) Obesity and liver disease: the epidemic of the twenty-first century. Clin. Liver Dis. 18, 1-18 CrossRef PubMed

2 Anstee, Q.M., Targher, G. and Day, C.P. (2013) Progression of NAFLD to diabetes mellitus, cardiovascular disease or cirrhosis. Nat. Rev. Gastroenterol. Hepatol. 10, 330-344 $\underline{\text { CrossRef PubMed }}$

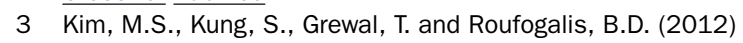
Methodologies for investigating natural medicines for the treatment of nonalcoholic fatty liver disease (NAFLD). Curr. Pharm. Biotechnol. 13, 278-291 CrossRef PubMed

4 Tillhon, M., Guaman Ortiz, L.M., Lombardi, P. and Scovassi, A.I. (2012) Berberine: new perspectives for old remedies. Biochem. Pharmacol. 84, 1260-1267 CrossRef PubMed

5 Li, Z., Geng, Y.N., Jiang, J.D. and Kong, W.J. (2014) Antioxidant and anti-inflammatory activities of berberine in the treatment of diabetes mellitus. Evid. Based Complement. Alternat. Med. 2014, 289264 PubMed

6 Kong, W., Wei, J., Abidi, P., Lin, M., Inaba, S., Li, C., Wang, Y., Wang, Z., Si, S., Pan, H. et al. (2004) Berberine is a novel cholesterol-lowering drug working through a unique mechanism distinct from statins. Nat. Med. 10, 1344-1351 CrossRef PubMed

7 Zhao, H.L., Sui, Y., Qiao, C.F., Yip, K.Y., Leung, R.K., Tsui, S.K., Lee, H.M., Wong, H.K., Zhu, X., Siu, J.J. et al. (2012) Sustained antidiabetic effects of a berberine-containing Chinese herbal medicine through regulation of hepatic gene expression. Diabetes 61, 933-943 CrossRef PubMed

8 Jung, H.A., Min, B.S., Yokozawa, T., Lee, J.H., Kim, Y.S. and Choi, J.S. (2009) Anti-Alzheimer and antioxidant activities of Coptidis rhizoma alkaloids. Biol. Pharm. Bull. 32, 1433-1438 CrossRef PubMed

9 Ye, X., Feng, Y., Tong, Y., Ng, K.M., Tsao, S., Lau, G.K., Sze, C., Zhang, Y., Tang, J., Shen, J. and Kobayashi, S. (2009) Hepatoprotective effects of Coptidis rhizoma aqueous extract on carbon tetrachloride-induced acute liver hepatotoxicity in rats. J. Ethnopharmacol. 124, 130-136 CrossRef PubMed

10 Lu, J., Wang, J.S. and Kong, L.Y. (2011) Anti-inflammatory effects of Huang-Lian-Jie-Du decoction, its two fractions and four typical compounds. J. Ethnopharmacol. 134, 911-918 CrossRef PubMed

11 Yu, H.H., Kim, K.J., Cha, J.D., Kim, H.K., Lee, Y.E., Choi, N.Y. and You, Y.O. (2005) Antimicrobial activity of berberine alone and in combination with ampicillin or oxacillin against methicillin-resistant Staphylococcus aureus. J. Med. Food. 8, 454-461 CrossRef PubMed

12 Tang, F., Wang, D., Duan, C., Huang, D., Wu, Y., Chen, Y., Wang, W., Xie, C., Meng, J., Wang, L. et al. (2009) Berberine inhibits metastasis of nasopharyngeal carcinoma $5-8 \mathrm{~F}$ cells by targeting Rho kinase-mediated Ezrin phosphorylation at threonine 567. J. Biol. Chem. 284, 27456-27466 CrossRef PubMed

13 Marra, F. and Lotersztajn, S. (2013) Pathophysiology of NASH: perspectives for a targeted treatment. Curr. Pharm. Des. 19, 5250-5269 CrossRef PubMed

14 Provenzano, A., Milani, S., Vizzutti, F., Delogu, W., Navari, N., Novo, E., Maggiora, M., Maurino, V., Laffi, G., Parola, M. and Marra, F. (2014) $n-3$ polyunsaturated fatty acids worsen inflammation and fibrosis in experimental nonalcoholic steatohepatitis. Liver Int. 34, 918-930 CrossRef PubMed

15 Rovida, E., Di Maira, G., Tusa, I., Cannito, S., Paternostro, C., Navari, N., Vivoli, E., Deng, X., Gray, N.S., Esparís-Ogando, A. et al. (2015) The mitogen-activated protein kinase ERK5 regulates the development and growth of hepatocellular carcinoma. Gut $\mathbf{6 4}, 1454-1465$ CrossRef PubMed 
16 Sutti, S., Jindal, A., Locatelli, I., Vacchiano, M., Gigliotti, L., Bozzola, C. and Albano, E. (2014) Adaptive immune responses triggered by oxidative stress contribute to hepatic inflammation in NASH. Hepatology 59, 886-897 CrossRef PubMed

17 London, R.M. and George, J. (2007) Pathogenesis of NASH: animal models. Clin. Liver Dis. 11, 55-74 CrossRef PubMed

18 Csak, T., Ganz, M., Pespisa, J., Kodys, K., Dolganiuc, A. and Szabo, G. (2011) Fatty acid and endotoxin activate inflammasomes in mouse hepatocytes that release danger signals to stimulate immune cells. Hepatology 54, 133-144 CrossRef PubMed

19 Imaeda, A.B., Watanabe, A., Sohail, M.A., Mahmood, S., Mohamadnejad, M., Sutterwala, F.S., Flavell, R.A. and Mehal, W.Z. (2009) Acetaminophen-induced hepatotoxicity in mice is dependent on TIr9 and the Nalp3 inflammasome. J. Clin. Invest. 119, 305-314 PubMed

20 Mo, C., Wang, L., Zhang, J., Numazawa, S., Tang, H., Tang, X., Han, X., Li, J., Yang, M., Wang, Z. et al. (2014) The crosstalk between Nrf2 and AMPK signal pathways is important for the anti-inflammatory effect of berberine in LPS-stimulated macrophages and endotoxin-shocked mice. Antioxid. Redox Signal. 20, 574-588 CrossRef PubMed

21 Kubes, P. and Mehal, W.Z. (2012) Sterile inflammation in the liver. Gastroenterology 143, 1158-1172 CrossRef PubMed

22 Zhang, X., Zhang, X., Wang, C., Li, Y., Dong, L., Cui, L., Wang, L., Liu, Z., Qiao, H., Zhu, C. et al. (2012) Neuroprotection of early and short-time applying berberine in the acute phase of cerebral ischemia: up-regulated pAkt, pGSK and pCREB, down-regulated NF- $\kappa$ B expression, ameliorated BBB permeability. Brain Res. 1459, 61-70 CrossRef PubMed

23 Chitra, P., Saiprasad, G., Manikandan, R. and Sudhandiran, G. (2013) Berberine attenuates bleomycin induced pulmonary toxicity and fibrosis via suppressing NF- $\kappa$ B dependant TGF- $\beta$ activation: a biphasic experimental study. Toxicol. Lett. 219, 178-193 CrossRef PubMed

24 Schroder, K. and Tschopp, J. (2010) The inflammasomes. Cell 140, 821-832 CrossRef PubMed

25 Barnes, P.M., Bloom, B. and Nahin, R.L. (2008) Complementary and alternative medicine use among adults and children: United States, 2007. Natl. Health Stat. Report 1-23

26 Yu, R., Zhang, Z.Q., Wang, B., Jiang, H.X., Cheng, L. and Shen, L.M. (2014) Berberine-induced apoptotic and autophagic death of HepG2 cells requires AMPK activation. Cancer Cell Int 14, 49 CrossRef PubMed
27 Yan, H.M., Xia, M.F., Wang, Y., Chang, X.X., Yao, X.Z., Rao, S.X., Zeng, M.S., Tu, Y.F., Feng, R., Jia, W.P. et al. (2015) Efficacy of berberine in patients with non-alcoholic fatty liver disease. PLoS One 10, e0134172 CrossRef PubMed

28 Shin, K.S., Choi, H.S., Zhao, T.T., Suh, K.H., Kwon, I.H., Choi, S.O. and Lee, M.K. (2013) Neurotoxic effects of berberine on long-term L-DOPA administration in 6-hydroxydopamine-lesioned rat model of Parkinson's disease. Arch. Pharm. Res. 36, 759-767 CrossRef PubMed

29 Henao-Mejia, J., Elinav, E., Thaiss, C.A. and Flavell, R.A. (2014) Inflammasomes and metabolic disease. Annu. Rev. Physiol. 76, 57-78 CrossRef PubMed

30 Wree, A., Eguchi, A., McGeough, M.D., Pena, C.A., Johnson, C.D., Canbay, A., Hoffman, H.M. and Feldstein, A.E. (2014) NLRP3 inflammasome activation results in hepatocyte pyroptosis, liver inflammation, and fibrosis in mice. Hepatology 59, 898-910 CrossRef PubMed

31 Skeldon, A. and Saleh, M. (2011) The inflammasomes: molecular effectors of host resistance against bacterial, viral, parasitic, and fungal infections. Front. Microbiol. 2, 15 CrossRef PubMed

32 Mariathasan, S., Weiss, D.S., Newton, K., McBride, J., O'Rourke, K., Roose-Girma, M., Lee, W.P., Weinrauch, Y., Monack, D.M. and Dixit, V.M. (2006) Cryopyrin activates the inflammasome in response to toxins and ATP. Nature 440, 228-232 CrossRef PubMed

33 Lee, G.E., Lee, H.S., Lee, S.D., Kim, J.H., Kim, W.K. and Kim, Y.C. (2009) Synthesis and structure-activity relationships of novel, substituted 5,6-dihydrodibenzo[a,g]quinolizinium $\mathrm{P}_{2} \mathrm{X}_{7}$ antagonists. Bioorg. Med. Chem. Lett. 19, 954-958 CrossRef PubMed

34 Lee, G.E., Lee, W.G., Lee, S.Y., Lee, C.R., Park, C.S., Chang, S. Park, S.G., Song, M.R. and Kim, Y.C. (2011) Characterization of protoberberine analogs employed as novel human $\mathrm{P}_{2} \mathrm{X}_{7}$ receptor antagonists. Toxicol. Appl. Pharmacol. 252, 192-200 CrossRef PubMed

35 Shemon, A.N., Sluyter, R., Conigrave, A.D. and Wiley, J.S. (2004) Chelerythrine and other benzophenanthridine alkaloids block the human $\mathrm{P}_{2 X_{7}}$ receptor. Br. J. Pharmacol. 142, 1015-1019 CrossRef PubMed

36 Henao-Mejia, J., Elinav, E., Jin, C., Hao, L., Mehal, W.Z., Strowig, T., Thaiss, C.A., Kau, A.L., Eisenbarth, S.C., Jurczak, M.J. et al. (2012) Inflammasome-mediated dysbiosis regulates progression of NAFLD and obesity. Nature 482, 179-185 PubMed 